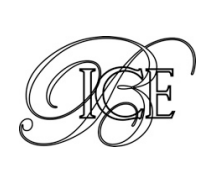

\author{
Esther del Campo* \\ Ruth Ferrero-Turrión ${ }^{* *}$
}

\title{
INTRODUCCIÓN Y PRESENTACIÓN
}

El pasado 9 de noviembre de 2014 se conmemoraron los veinticinco años de la caída del Muro de Berlín y del fin de la guerra fría. Terminaba entonces una época, la del mundo bipolar nacido de los acuerdos de Yalta y Postdam, y comenzaba una nueva etapa histórica no dominada ya por la pugna entre capitalismo y socialismo, sino por el conflicto entre integrismos, así como por el estallido de la más importante crisis financiera internacional desde la Gran Depresión, que ha significado en última instancia una crisis sistémica global, que ha hecho más necesaria y urgente la búsqueda de nuevas formas de gobernanza mundial. En el ámbito europeo se inauguraba una nueva era entre los países europeos, y entre éstos y el resto del mundo.

La caída del Muro de Berlín abrió la caja de Pandora de una serie de importante acontecimientos que comenzarían con la reunificación de Alemania en 1990, seguirían con las Guerras en los Balcanes y continuarían con la ampliación de la Unión Europea (UE) hacia el Este; proceso en el que aún nos encontramos, a la espera de la incorporación de los Balcanes Occidentales a las instituciones europeas, todo ello sin olvidarnos de la crisis existente en la frontera oriental a raíz de la guerra en Ucrania y el enfrentamiento geoestratégico abierto con Rusia.

Efectivamente, con la reunificación alemana comenzó un masivo esfuerzo, tanto político como económico y social, gracias al cual, Alemania es hoy la principal fuerza económica y política, el llamado «motor de la Unión Europea». Con la caída de los regímenes comunistas se puso fin a la división de Europa, herencia de la postguerra. Una división que reflejaba más la posición militar de las potencias vencedoras en 1945, que una realidad geográfica, cultural o histórica. También regresaron los conflictos nacionales en Yugoslavia o la URSS, la desintegración de Estados -caso de Checoslovaquia- o la aparición de otros nuevos como Croacia y Bosnia.

Quizás, uno de los principales resultados de este proceso histórico ha sido la incorporación a las instituciones europeas y, por ende, a las estructuras militares de la OTAN de la gran mayoría de los Estados de Europa central y oriental. Este cambio fundamental no sólo ha afectado a estos países, sino que estas transformaciones han transcendido y han tenido un fuerte impacto en la estabilidad internacional, tal y como hemos podido comprobar a lo largo del último año con la crisis desatada en Ucrania, pero también durante el conflicto de Georgia de 2008, o con la todavía no resuelta situación en Kosovo.

Son precisamente estos cambios en la manera de relacionarse Europa entre sí y con el mundo lo que se pretende revisar desde este número monográfico dedicado en su totalidad a analizar las relaciones $\square$

\footnotetext{
* Catedrática de Ciencia Política y Directora del Instituto Complutense de Estudios Intenacionales (ICEI).

** Profesora de Ciencia Política e Investigadora Senior en el Insituto Complutense de Estudios Intenacionales(ICEI).
} 
políticas y económicas en el seno de la Unión Europea. Relaciones que se han visto modificadas por la incorporación a las instituciones europeas de estos nuevos países de la Europa central y oriental, y que, además, han hecho que se moviera la frontera europea generando roces con el vecino ruso. A lo largo de las páginas de este monográfico encontramos a través de distintos enfoques y disciplinas un análisis pormenorizado del contexto, situación actual y prospectiva ante los nuevos retos que se plantean tanto dentro de la UE como entre la UE y la Federación Rusa.

Así, el monográfico comienza con un artículo dedicado a la contextualización del nuevo orden global que es precisamente el que va a determinar las nuevas reglas del juego dentro del viejo continente, elaborado por Cristina Manzano, para inmediatamente dar paso a dos artículos centrados en el proceso de ampliación: el primero de ellos, elaborado por Almudena López, sobre la situación en la que se encuentran los actuales países candidatos y sus perspectivas de incorporación a la Unión; y el segundo, que analiza el impacto que el inicio de nuevos movimientos migratorios intra-europeos ha tenido y tiene en la forma de hacer política tanto en los Estados miembros, como a nivel de la Unión, donde ha llegado incluso a plantearse el fin de la libertad de movimiento de personas. Siguiendo la estela de estos análisis más políticos, los siguientes artículos se centran en dos cuestiones fundamentales de tipo más económico: el offshoring como nueva estrategia de deslocalización empresarial, elaborado por Esmeralda Linares, y los procesos de transición, esta vez, del régimen cambiario hacia el euro de los países del centro y este de Europa, artículo escrito por Simón Sosvilla y $\mathrm{M}^{\mathrm{a}}$ del Carmen Ramos.

Por último, el número se completa con tres artículos que se centran en las relaciones de la Unión Europea con terceros actores. El artículo de Francisco J. Ruiz-González, analiza el actual statu quo de las relaciones de la UE con la Federación Rusa, planteando que más allá de los conflictos que venimos observando en la vecindad común, existen otras crisis de índole global que hacen necesaria una estrecha cooperación entre ambos. Por su parte, Juan José Otamendi nos cuenta cual ha sido el impacto que ha tenido en España la política de sanciones impuesta por la Unión Europea a Rusia como consecuencia de la crisis en Ucrania. Y para finalizar, el artículo de Rubén Ruiz Ramas traza una semblanza de la situación política de los países de Asia central, países que se encuentran en una tensión permanente entre el autoritarismo y la democracia liberal provocando una reducida estabilidad política y, por tanto, convirtiendo en más complejas las relaciones con estos países que son potenciales socios comerciales de la Unión Europea.

De este modo, este número pretende ir más allá de los análisis tradicionales realizados desde España y que, en muchas ocasiones se quedaron en aquello que Tony Judt bautizó como "el retorno a Europa". El monográfico pretende explicar los cambios que se han sucedido en estos 25 años desde un enfoque multidisciplinar, abordando la complejidad de los procesos y del contexto con una amplitud de miras que nos permitan ver más allá de estos análisis tradicionales. Consideramos pues, que ya el regreso a una Europa convertida en mito con un proyecto común continental se ha tornado una cuestión mucho más compleja y con repercusiones que sobrepasan la unidad continental. 